\title{
Physical Activity and Cancer Survivorship
}

\author{
David O. Garcia, PhD $^{1}$ and Cynthia A. Thomson, PhD, RD 1 \\ ${ }^{1}$ Canyon Ranch Center for Prevention and Health Promotion, Mel \& Enid Zuckerman College of \\ Public Health, Division of Health Promotion Sciences, University of Arizona, Tucson, Arizona
}

\section{Abstract}

There has been an increase in the cancer survivor population in the United States over the past several decades primarily due to improvements in early detection of first malignancies and effective treatment modalities. A wealth of evidence has demonstrated that regular physical activity is associated with a lower risk of death, all-cause mortality, cancer recurrence, and several chronic diseases, including type 2 diabetes and cardiovascular disease, common comorbid conditions in people who have survived cancer. Physical activity also is a central component of weight management.

Methods-This review summarizes the current physical activity recommendations and the evidence linking physical activity to improvements in weight management, physiological effects, and psychological health outcomes for cancer survivors.

Results-The available literature suggests physical activity is safe and is positively associated with weight management, cardiorespiratory fitness, muscular strength and endurance, quality of life, fatigue, and other psychosocial factors in cancer survivors. Yet relationships related to specific cancer diagnoses, treatments, and underlying cardiometabolic mechanisms associated with survival have not been thoroughly examined in randomized controlled trials. Furthermore, factors that influence adherence to physical activity behaviors must be identified to develop effective exercise programs. The use of objective measures of physical activity and the standardization of reporting outcome measures within intervention trials are needed to complement this effort.

Conclusions-Healthcare providers should consider individual differences among cancer survivors and tailor physical activity programs to meet the individual needs of the patient to assist in the adoption and maintenance of a physically active lifestyle.

\section{Keywords}

survival; neoplasms; exercise; obesity; cancer

According to the Centers for Disease Control and Prevention, a cancer survivor is defined as anyone who has been diagnosed with cancer, from the time of diagnosis through the

(C) 2014 American Society for Parenteral and Enteral Nutrition

Corresponding Author: David O. Garcia, PhD, Canyon Ranch Center for Prevention and Health Promotion, Mel \& Enid Zuckerman College of Public Health, Division of Health Promotion Sciences, University of Arizona, 3950 S. Country Club, Suite 330, Tucson, AZ 85714, USA. davidogarcia@email.arizona.edu. 
remainder of his or her life. ${ }^{1}$ It is estimated that there are approximately 14.5 million cancer survivors alive in the United States, and this number is expected to rise to 19 million by $2024 .^{2-4}$ The increase in the cancer survivor population is largely attributed to improvements in early detection of first malignancies and effective treatment modalities. ${ }^{5}$ Consequently, the 5-year relative survival rate after cancer diagnosis for all cancers is $68 \%$, which reflects a $19 \%$ improvement over the past 2 decades. ${ }^{2}$ The aging population of the United States also is contributing to the rise in the cancer survivor population since the incidence of most cancers increases with age. ${ }^{6}$ In fact, it is estimated that nearly $63 \%$ of cancer survivors will be 65 years or older by $2020 .^{7,8}$ The increase in the cancer survivor population parallels the obesity epidemic in the United States, with $69 \%$ of adults classified as overweight (body mass index [BMI] $\geq 25.0 \mathrm{~kg} / \mathrm{m}^{2}$ ) and $35.1 \%$ as obese (BMI $\geq 30.0$ $\left.\mathrm{kg} / \mathrm{m}^{2}\right) .{ }^{9}$ As a result, most cancer survivors are more likely to be overweight or obese at the time of diagnosis. Obesity at the time of cancer diagnosis has been associated with poorer prognosis, and weight gain in combination with radiation and chemotherapy in survivors appears to accelerate obesity-associated chronic disease. ${ }^{10}$ Therefore, weight management is a priority for cancer survivors. ${ }^{11}$

The paradigm shift in the cancer care treatment community from disease-focused to wellness-comprehensive care affords a unique opportunity for healthcare providers to promote healthy lifestyle behaviors for cancer survivors. ${ }^{11,12}$ Physical activity is a modifiable lifestyle behavior positively associated with weight management and numerous physiologic effects and psychological health outcomes such as cardiorespiratory fitness, fatigue, and quality of life. ${ }^{13-17}$ In addition, several reviews and meta-analyses have demonstrated that physical activity is associated with a lower risk of death, all-cause mortality, and cancer recurrence, particularly among breast and colorectal cancer survivors. ${ }^{18-20}$ Physical activity also reduces other comorbid chronic diseases such as type 2 diabetes and cardiovascular disease. ${ }^{11,21}$ Despite this evidence, it is estimated that $<10 \%$ of cancer survivors will be active during treatments and only $20 \%-30 \%$ will be active after treatments. ${ }^{22,23}$ This suggests healthcare providers should develop a working knowledge of the role of physical activity in cancer survivorship (Figure 1) to help patients adopt and maintain a physically active lifestyle. ${ }^{24-26}$ This review aims to summarize the current physical activity recommendations and the evidence linking physical activity to improvements in weight management, physiological effects, and psychological health outcomes for cancer survivors.

\section{Physical Activity Guidelines for Cancer Survivors}

In 2003, the American Cancer Society (ACS) published the first report to provide healthcare providers and cancer survivors with guidance for physical activity (Table 1). ${ }^{27}$ The report suggested that cancer survivors follow the guidelines for cancer prevention (eg, at least 30 minutes of moderate to vigorous physical activity at least 5 days per week above usual activities; 45-60 minutes of intentional physical activity is preferred) as soon as it is safe to do so, even while undergoing adjuvant treatment such as chemotherapy or radiation. For reference, a moderate-intensity activity is similar to a brisk walk, while a vigorous-intensity activity is similar to a jog/run (Table 2) ${ }^{28,29}$ In 2006, the ACS report was updated to highlight the importance of daily and regular physical activity and encouraged steps to move 
from a sedentary to an active life-style. ${ }^{30}$ In 2009, the American College of Sports Medicine (ACSM) convened a roundtable of clinical and research experts in the field of cancer and exercise to develop exercise testing and prescription specifically for cancer survivors. ${ }^{31}$ The panel concluded that cancer survivors should adopt the aerobic, resistance training, and flexibility activities consistent with the age-appropriate guidelines for adults from the U.S> Department of Health and Human Services ${ }^{32}$ and the American Heart Association/ACSM (Table 1) ${ }^{33}$ In 2012, the most recent update to the ACS report concluded that survivors should follow the survivor-specific guidelines written by the ACSM expert panel. ${ }^{11}$ Despite these recommendations and numerous benefits of physical activity, only one-third of cancer survivors achieve these guidelines. ${ }^{34-36}$ One possible reason for low adherence rates in this population is that interest in, preferences for, and tolerance of physical activity vary among cancer survivors, and there is a need to personalize the guidelines to meet the individual's needs. ${ }^{24}$ Therefore, the current health status of cancer survivors, treatments, and anticipated disease trajectories should be considered to determine appropriate physical activity recommendations for cancer survivors. ${ }^{31}$

\section{Cancer-Specific Safety Precautions and Contraindications}

The limited evidence to issue specific guidelines for contraindications and safety precautions for physical activity in cancer survivors often leaves healthcare providers to make judgments based on their previous clinical experience. ${ }^{24}$ Previous research suggests that physical activity is well tolerated during and after treatment without adverse events. ${ }^{37}$ Furthermore, particular health issues related to cancer treatment affecting a survivor's ability to engage in physical activity have been identified. For instance, the ACS reports identified that specific precautions should be undertaken for survivors with severe anemia, comprised immune function, severe fatigue, indwelling catheters, and peripheral neuropathies or ataxia (Table 3). ${ }^{11}$ Furthermore, the ACSM report identified appropriate safety cautions for survivors at risk for lymphedema and skeletal muscle fractures or infections. Several contraindications for physical activity, including arm and shoulder problems secondary to breast cancer treatment, having an ostomy after colon cancer, or swelling/inflammation in the abdomen, groin, or lower extremity following gynecologic cancer, were also acknowledged. ${ }^{31}$ Importantly, when considering physical activity prescriptions for patients, the risks of participating in physical activity must be balanced against the risks of inactivity. For instance, several trials have demonstrated that physical activity reduces the incidence and severity of lymphedema. ${ }^{38,39}$ At a minimum, healthcare providers should counsel survivors to decrease sedentary behaviors as much as possible and consider physical activity prescriptions that take into account individual capabilities. ${ }^{40}$

\section{Physical Activity Interventions}

Given the unique health issues faced by cancer survivors, earlier work focused largely on evaluating the feasibility, tolerance, and acceptance of physical activity interventions in the cancer survivor population. Several studies of this nature are described below, the majority of which support integration of physical activity into the routine clinical care of cancer survivors. 
In the FRESH START trial, breast and prostate cancer survivors $(n=543)$ were randomly assigned to either a home-based tailored mailed print intervention to improve diet and physical behaviors or a standard-care control condition. ${ }^{41}$ With regard to physical activity, greater improvements were observed in the tailored print intervention $(+59.3 \mathrm{~min} / \mathrm{wk})$ compared with the control condition ( $+39.2 \mathrm{~min} / \mathrm{wk})$ and led the authors to conclude that a home-based intervention may be an acceptable method to assist cancer survivors to pursue a healthy lifestyle. The Yale Exercise and Survivorship Study recruited 75 breast cancer survivors to participate in a combination of a supervised gym-based and home-based aerobic exercise intervention compared with a usual-care group. ${ }^{42}$ The results suggested physical activity after diagnosis of breast cancer is feasible, with the exercise group increasing physical activity (+129 min/wk) compared with the usual-care group ( $+44 \mathrm{~min} / \mathrm{wk})$. The Prostate Cancer Survivors Motivated to Exercise (PROMOTE) trial was one of the first to examine the utility of an implementation intervention for increasing activity in any cancer survivor group. ${ }^{43}$ Prostate cancer survivors $(n=423)$ were randomized to 1 of 3 groups: a standard physical activity recommendation group, self-administered implementation intention (weekly goal setting), or a telephone-assisted implementation intention. ${ }^{43}$ The authors found that physical activity at the 3-month follow-up increased by $180 \mathrm{~min} / \mathrm{wk}$ in the self-administered implementation intention group compared with $100 \mathrm{~min} / \mathrm{wk}$ in the standard physical activity recommendation group. These results suggest that a selfadministered implementation intervention may have positive short-term effects on selfreported physical activity in prostate cancer survivors. Currently, the Colon Health and LifeLong Exercise Challenge (CHALLENGE) trial is examining behavioral change techniques delivered more frequently on the effects of physical activity behaviors long term among survivors who completed adjuvant therapy ${ }^{44}$ Future studies should explore factors that influence adherence to physical activity behaviors to develop effective exercise programs designed to increase physical activity behaviors.

\section{Physical Activity and Weight Management}

To understand the obesity epidemic, it is helpful to examine how body weight is regulated. ${ }^{45}$ Energy balance is determined by the amount of energy consumed (caloric intake) in relation to the amount of energy expended in physical activity and metabolism. ${ }^{46-48}$ To lose weight, individuals must obtain a negative energy balance in which energy expenditure exceeds energy intake, whereas weight gain is a result of a positive energy balance in which energy intake exceeds energy expenditure. Finally, to maintain a stable body weight, energy expenditure must equal energy intake over time. Physical activity is the most variable and modifiable component of the energy balance equation, with 10\%-30\% of total daily energy expenditure resulting from activities of daily living and structured exercise. ${ }^{49}$ Thus, it is a central component of weight management in the prevention of weight gain, weight loss, and the prevention of regain after weight loss.

A growing body of evidence has examined the effect of physical activity on weight management in cancer survivor populations. The Can Change trial enrolled 410 colorectal cancer survivors to a health coaching intervention or a usual-care group. ${ }^{50}$ The health coaching intervention consisted of 11 theory-based telephone-delivered health coaching sessions over 6 months focusing on physical activity, weight management, dietary habits, 
alcohol, and smoking. At the 12-month follow-up, improvements in moderate-intensity physical activity $(28.5 \mathrm{~min} / \mathrm{wk})$ and BMI $\left(-0.9 \mathrm{~kg} / \mathrm{m}^{2}\right)$ were demonstrated. The Reach Out to Enhance Wellness (RENEW) trial ${ }^{51}$ enrolled 641 older adult colorectal, breast, and prostate cancer survivors from the United States, Canada, and the United Kingdom. The study tested a 12-month home-based exercise intervention delivered via print material and telephone counseling with a 12-month follow-up. While the primary outcome was change in physical function, significant improvements were observed for BMI from baseline to followup in both groups. Similar findings were shown in survivors of uterine cancer. The Survivors of Uterine CanCer Empowered by Exercise and Healthy Diet (SUCCEED) trial ${ }^{52}$ was designed to evaluate a comprehensive 6-month lifestyle intervention in promoting weight loss and a healthy lifestyle, including increasing physical activity compared with a usual-care control group in 75 survivors. The intervention was conducted over 16 group sessions ( 10 weekly followed by 6 biweekly) with physician face-to-face counseling visits at 3,6 , and 12 months. Significant differences in weight change were observed from baseline to 6 months ( $-4.4 \mathrm{~kg}$ [ -5.3 to -3.5$])$ and 12 months ( $-4.6 \mathrm{~kg}[-5.8$ to -3.5$])$. Independent of weight outcomes, physical activity can minimize sarcopenia, a decrease in skeletal muscle mass related to aging. ${ }^{53}$ During treatment, sarcopenia is associated with chemotherapy toxicity and metastatic tumor progression. ${ }^{54,55}$ Furthermore, sarcopenic obesity, a decrease in muscle mass as body fat mass increases, is prevalent among patients who undergo chemotherapy. ${ }^{56,57}$ After treatment, sarcopenia affects physical function, mobility, and overall mortality. ${ }^{58,59}$ Thus, the development of physical activity interventions to maintain and/or improve both weight outcomes and skeletal muscle mass for obesity-associated cancers warrants further study.

\section{Measurement Considerations}

Physical activity is a complex and multidimensional construct, making it difficult to measure ${ }^{60}$ Due to methodological considerations, self-report including questionnaires and activity logs is the primary method used within physical activity interventions to assess adherence to exercise prescriptions and to examine associations for health outcomes. ${ }^{61}$ Adherence rates, often defined as the percentage of participants who met a minimum criterion of moderate to vigorous exercise per week (eg, $150 \mathrm{~min} / \mathrm{wk}$ ), have ranged from $33 \%$ in breast cancer survivors to $41.9 \%$ in colorectal cancer survivors in home-based exercise programs. ${ }^{62,63}$ Mixed findings also are observed among population-based studies using self-reported methods. For example, an analysis from the Women's Health Initiative (WHI) study demonstrated that higher levels of self-reported physical activity may improve survival in postmenopausal women with breast cancer, even among those reporting low physical activity prior to diagnosis. ${ }^{64}$ In contrast, self-reported data from the Life After Cancer Epidemiology (LACE) study did not support a protective effect of physical activity on breast cancer recurrence and mortality in survivors. ${ }^{65}$ It has been suggested that the reliance on self-reported data of physical activity may contribute to the inconsistency of these findings. ${ }^{66,67}$ Due to differences in dose-response relationships related to specific cancer diagnoses and treatments, there is a need to standardize methods of physical activity interventions, as well as measure and report outcome measures. ${ }^{68}$ This will allow 
researchers and clinicians to identify correlates, determinants, and potential mediators of physical activity. ${ }^{60}$

Objective methods such as pedometers and accelerometers have emerged as preferred methods to measure physical activity levels. Pedometers encourage physical activity through improvements in daily steps and have been integrated into interventions to assess lifestyle physical activity and individually tailored programs. ${ }^{69-71}$ Despite their utility, pedometers have limited ability to assess the intensity levels of physical activities. In comparison, accelerometers can estimate the duration and intensity of activity bouts. This is important as recent evidence suggests that light-intensity activities are beneficial for cancer survivors, particularly to reduce the rate of physical function decline for those who are unable to initiate or maintain moderate-intensity activities. ${ }^{72}$ A meta-analysis of 56 trials comparing participants randomized to an exercise $(n=2286)$ or comparison $(n=1985)$ group found that improvements in quality of life (QoL) and physical functioning, social functioning, and fatigue were more pronounced with moderate- or vigorous-intensity vs mild-intensity exercise programs. ${ }^{73}$ Therefore, the measurement of physical activity using an accelerometer may be a more useful assessment of changes in physical activity intensity to assess the efficacy of physical activity interventions. ${ }^{74}$ Furthermore, accelerometers may be used within clinical assessments for cancer survivors to provide feedback on physical activity behaviors. ${ }^{75,76}$ However, the feasibility and practicality of this method have not been well evaluated and warrant further investigation.

\section{Physiological Effects of Physical Activity}

\section{Cardiorespiratory Fitness}

Cardiorespiratory fitness is the ability of the circulatory and respiratory systems to deliver oxygen to the metabolically active skeletal muscles during physical activity. It has been measured by peak oxygen consumption, functional tests (eg, walk/step test), and submaximal fitness tests (eg, graded treadmill test) in breast, ${ }^{77}$ colorectal, ${ }^{78}$ prostate, ${ }^{79}$ hematologic, ${ }^{80}$ and mixed cancer survivors. ${ }^{37}$ Generally expressed in metabolic equivalent tasks (METs) or maximal oxygen uptake $\left(\mathrm{VO}_{2} \mathrm{max}\right)$, it is considered a reliable measure of habitual physical activity levels and improves insulin sensitivity, blood lipid profiles, inflammation, and blood pressure. ${ }^{81}$ It also is considered a strong predictor of mortality in cancer survivors. 82

While treatment may impair cardiorespiratory fitness, there is sufficient evidence to suggest aerobic training improves cardiorespiratory fitness among cancer survivors. ${ }^{38,83}$ For example, the Exercise for Health randomized controlled trial enrolled 194 women with a first diagnosis of invasive breast cancer to a usual-care $(n=60)$, face-to-face $(n=67)$, or over-the-telephone $(n=67)$ exercise group 6 weeks after breast cancer surgery. ${ }^{84}$ Briefly, the intervention included 16 scheduled sessions either in person or via telephone with an exercise physiologist, starting weekly and tapering to monthly contacts after 4 months. The overall goal was to accumulate 180 minutes of exercise per week (at least 4 days per week for 45 minutes), in addition to incorporating strength-based exercises 2 days a week. Starting parameters and rate of progression were individually tailored, taking into account initial fitness levels, presence of treatment-related side effects, and exercise preferences. 
Cardiorespiratory fitness was assessed using a 3-minute step test, with lower heart rates indicating higher fitness levels. At 1 year after intervention, the face-to-face and telephone groups demonstrated significant improvements in cardiorespiratory fitness ( -9.0 and -6.3 beats per minute, respectively) compared with the usual-care group ( +2.7 beats per minute).

Another randomized controlled trial examined the effect of a 12-week aerobic and resistance training exercise program plus dietary advice $(\mathrm{n}=25)$ compared with standard care $(\mathrm{n}=25)$ in men with advanced prostate cancer receiving androgen suppression therapy (AST). ${ }^{85}$ Men attended 2 supervised exercise sessions for the initial 6 weeks and then one weekly for the following 6 weeks. The exercise sessions comprised 30 minutes of aerobic exercise at an intensity level of 55\%-85\% age-predicted maximal heart rate with an exercise physiologist. In addition, they were prescribed self-directed exercise such as a brisk walk for at least one 30-minute session per week during the first 6 weeks and 2 during the final 6 weeks, using a $\log$ book to record activity to promote behavior change. Aerobic exercise tolerance was assessed using a Bruce ramp protocol, with time on the treadmill to number 15 (hard) on the Borg Rating of Perceived Exertion (RPE) recorded as the termination point. The investigators found that men in the intervention group achieved a significant improvement in aerobic exercise tolerance compared with the standard-care condition, results that suggest the potential to improve cardiovascular fitness long term.

\section{Muscular Strength and Endurance}

Cancer treatment often results in decreases in physical activity, and subsequent decreases are observed in muscular performance. The evidence suggesting resistance training to improve muscular strength and endurance in cancer survivors continues to grow. ${ }^{86}$ Previous randomized controlled trials have assessed changes in upper and lower body strength using 1-repetition maximum tests, hand grip strength, and overhead or leg press. Most research on this topic has been conducted in breast cancer survivors to examine the effect of weight training on cancer-related lymphedema exacerbations, symptom severity, and bone density. ${ }^{87-90}$ For instance, a randomized controlled trial studying changes in body image following a 1-year strength training intervention for breast cancer survivors with or at risk for lymphedema found significant improvements in bench and leg press among treatment groups compared with control group participants, regardless of lymph-edema condition and with no adverse effects. ${ }^{91}$

Improvements in muscular strength have also been observed. A recent study of breast cancer survivors suggested that an 8-week aquatic program improves abdominal endurance and muscular leg strength. ${ }^{92}$ Resistance training also has been used for prostate cancer survivors receiving AST, which lowers testosterone levels, resulting in skeletal muscle and strength. ${ }^{85,93}$ In a 12-week resistance training study for men receiving AST, the resistance training significantly improved upper and lower body muscular strength and endurance compared with a usual-care group. ${ }^{94}$ Similar improvements were observed in prostate cancer survivors undergoing a supervised resistance training program measured by maximum voluntary torque by isokinetic dynamometry of the quadriceps. ${ }^{85}$ Overall, this evidence suggest that a combination of aerobic and resistance training will have a positive impact on health and should be recommended for cancer survivors. However, more research is needed 
to examine this relationship, particularly in relation to cancer recurrence and cancer mortality.

\section{Flexibility}

Cancer survivors often encounter decreases in range of motion, limiting physical function as a result of surgeries causing scarring and tissue damage. Currently, limited data have examined the effect of aerobic exercise training on flexibility in cancer survivors. ${ }^{78,95,96}$ In fact, only 1 small study in breast and colon cancer survivors $(n=18)$ is available, and results of this study demonstrated an improvement in flexibility between treatment and control patients. ${ }^{95}$ Other studies have evaluated the effects of alternative modes of physical activity on flexibility, including yoga, tai chi chuan, and stretching, on shoulder range of motion for breast cancer survivors. ${ }^{97-100}$ These studies yielded mixed findings, with only 1 showing significant between-group differences in shoulder range of motion. ${ }^{100}$ Future research is needed to determine the effects of training methods to improve flexibility.

\section{Cardiometabolic Biomarkers}

While studies evaluating the impact of physical activity interventions on cancer outcomes are limited, the evidence that a lifestyle including a healthy body weight, diet, and regular physical activity can modify metabolic indices as predictors of health status is available. For instance, among adult survivors of childhood cancer at risk for developing metabolic syndrome, a recent study demonstrated that women $(n=832)$ and men $(n=807)$ who did not follow the World Cancer Research Fund and the American Institute for Cancer Research guidelines were 2.4 and 2.2 times more likely to develop metabolic syndrome than those that did follow them, respectively. ${ }^{101,102}$ These findings suggest that children with cancer and adults who had cancer should engage in healthy lifestyle behaviors to influence their longterm health. Furthermore, physical activity and a healthy weight during adolescence also may reduce cancer risk in individuals susceptible to the diseases, such as BRCA gene mutation carriers. ${ }^{103}$

Importantly, several biological mechanisms may be affected by increased physical activity, resulting in changes in circulating adipokines, cytokines, insulin resistance, blood insulin levels, and sex hormone production. ${ }^{104,105}$ The greatest changes in cardiometabolic measures are seen in trials that integrate diet and activity with the goal of reducing body weight; however, exercise alone can improve these measures (Figure 2). The Health, Eating, Activity and Lifestyle (HEAL) study is the only observational cohort study that has evaluated the association between physical activity and biomarkers, including leptin, insulin-like growth factor (IGF), IGF-binding protein 3, and inflammatory markers (eg, Creactive protein), in breast cancer survivors. ${ }^{106,107}$ Blood samples and self-reported physical activity were obtained every $6-8$ months and $2-3$ years after diagnosis, with significant inverse associations between physical activity and circulating levels of leptin, insulin, and inflammatory markers observed. A recent systematic review examining the relationship of physical activity, biomarkers, and disease outcomes including randomized controlled trials $(\mathrm{n}=11)$ with biomarker end points suggests that exercise may result in beneficial changes in the circulating level of insulin, insulin-related pathways, inflammation, and potentially immunity. ${ }^{108}$ Yet most of the trials identified were not designed to examine biomarkers as 
the primary end point, with only 1 providing a sample size calculation to demonstrate it had sufficient statistical power to detect differences between treatment groups. ${ }^{108,109}$ Future research should address these limitations to determine the effect of physical activity on cardiometabolic biomarkers and to identify mechanistic pathways that may influence cancer survival.

\section{Psychological Benefits of Physical Activity}

\section{Quality of Life}

It is common practice among researchers examining physical activity interventions for cancer survivors after treatment to incorporate QoL measures such as the Function Assessment of Cancer Therapy Scale (FACT-G) and the breast cancer-specific scale (FACT-B). Evidence supports that physical activity interventions in cancer survivors have significant effects on overall QoL by improving physical and psychological functioning. ${ }^{51,110,111}$ A 2011 meta-analysis of 78 physical activity intervention trials demonstrated that clinically meaningful improvements in QoL persisted after the completion of the physical activity intervention. ${ }^{112}$ Subscales of QoL, including emotional, social, functional, physical, and mental QoL, also have been examined within this context, with results consistently showing that physical activity improves overall QoL in cancer survivors. Recent findings from the 6-month Steps to Health home-based exercise intervention in obese and non-obese endometrial cancer survivors revealed significant changes for physical aspects of QoL (physical functioning, energy levels, pain, and general health perceptions) and mental and emotional aspects such as stress, negative emotions, cognitive problems, and distress after recurrence. ${ }^{113}$ Another trial, Active for Life, was a randomized controlled trial that examined the efficacy of a 12-month group-based lifestyle physical activity program for patients with prostate cancer to improve QoL, including physical and emotional functioning, compared with a group-based emotional support program and standard-care program. ${ }^{114}$ For 6 months, participants in the lifestyle program attended in person group sessions that focused on increasing physical activity. While improvements were made in theoretical mediators proposed to affect physical activity levels, there were no improvements observed in QoL or physical activity at 6 months and at the 6-month follow-up. Conversely, Exercise for Health ${ }^{115}$ was an 8-month randomized controlled trial that evaluated a face-to-face and telephone-based translational exercise intervention compared with a usual-care group beginning 6 weeks after breast cancer surgery. The intervention consisted of 16 scheduled sessions (in person or via telephone) with a designated exercise physiologist, starting weekly and tapering to monthly contacts after 4 months, with the overall goal of progressing exercise to $180 \mathrm{~min} / \mathrm{wk}$ in addition to 2 days of strength-based exercise. Significant improvements were observed in QoL in both treatment groups compared with usual care. The inconsistency of these findings may be attributed to the variability observed in QoL observed during treatment. ${ }^{116}$ Thus, it appears the mechanisms underlying the relationship between physical activity and QoL are not well understood in cancer survivor populations, and future randomized controlled trials are needed to better understand this relationship. 


\section{Fatigue and Psychosocial Factors}

Cancer-related fatigue is a common side effect of treatment and can persist well after it is complete. Mechanisms of cancer-related fatigue are categorized into peripheral and central components. Peripheral fatigue occurs in muscle tissues due to a lack of adenosine triphosphate (ATP) and the buildup of metabolic by-products, resulting in the inability of the peripheral neuromuscular system to perform a task in response to a central stimulation. ${ }^{117}$ Central fatigue occurs in the central nervous system and results from the progressive failure to transmit motor neuron impulses, making it difficult to initiate and maintain voluntary activities. ${ }^{118,119}$

The course of cancer-related fatigue is well characterized, and there is evidence of biological mechanisms (proinflammatory cytokines and C-reactive protein), which may influence it during and after treatment. ${ }^{120,121}$ Yet, variability observed in cancer-related fatigue cannot be explained by disease-related or treatment-related characteristics. ${ }^{122}$

While the etiology of cancer-related fatigue remains unclear, it has a substantial impact on the survivor's sense of physical, emotional, and cognitive tiredness. ${ }^{123}$ Historically, clinicians advised patients to rest if they felt fatigued, but data have emerged demonstrating that increases in physical activity can improve cancer-related fatigue. ${ }^{50,92,124}$ Specifically, physical activity counteracts perceptions of fatigue by improving muscular strength, functional capacity, fitness, QoL, and psychosocial factors such as anxiety, depression, selfesteem, happiness, and body image. ${ }^{85,91,123,125,126}$ However, a recent meta-analysis of 56 studies examining this relationship found that beneficial effects were only identified following aerobic training but not following resistance training or alternative forms of physical activity (eg, tai chi). ${ }^{127}$ Furthermore, data are limited to breast and prostate cancer populations, and there is no clear evidence what type of cancer treatment alters the effects of exercise on cancer-related fatigue. ${ }^{127}$ Further research is required to determine the effects of different exercise modes on fatigue and psychosocial factors in a variety of cancer-specific survivor populations.

\section{Remaining Challenges/Research Gaps}

Physical activity promotes weight management and is positively associated with cardiorespiratory fitness, muscular strength and endurance, QoL, fatigue, and other psychosocial factors in cancer survivors. The available literature suggests physical activity is safe for cancer survivors, yet relationships related to specific cancer diagnoses, treatments, and underlying cardiometabolic mechanisms associated with survival have not been thoroughly examined in randomized controlled trials. Furthermore, factors that influence adherence to physical activity behaviors must be identified to develop effective exercise programs for cancer survivors. The use of objective measures of physical activity and the standardization of reporting outcome measures within intervention trials are needed to complement this effort. Importantly, healthcare providers should consider individual differences among cancer survivors and tailor physical activity programs to meet the individual needs of the patient to assist in the adoption and maintenance of a physically active lifestyle. 


\section{Acknowledgments}

Financial disclosure: National Cancer Institute (grant/award number: P30CA023074, R25CA078447).

\section{References}

1. Centers for Disease Control and Prevention. Cancer survivors-United States, 2007. MMWR Morb Mortal Wkly Rep. 2011; 60(9):269-272. [PubMed: 21389929]

2. Siegel R, Ma J, Zou Z, Jemal A. Cancer statistics, 2014. CA Cancer J Clin. 2014; 64(1):9-29. [PubMed: 24399786]

3. de Moor JS, Mariotto AB, Parry C, et al. Cancer survivors in the United States: prevalence across the survivorship trajectory and implications for care. Cancer Epidemiol Biomarkers Prev. 2013; 22(4):561-570. [PubMed: 23535024]

4. American Cancer Society. [Accessed June 8, 2014] Cancer treatment \& survivorship facts \& figures 2014-2015. http://www.cancer.org/research/cancerfactsstatistics/survivor-facts-figures

5. McCabe MS, Bhatia S, Oeffinger KC, et al. American Society of Clinical Oncology statement: achieving high-quality cancer survivorship care. J Clin Oncol. 2013; 31(5):631-640. [PubMed: 23295805]

6. White MC, Holman DM, Boehm JE, Peipins LA, Grossman M, Henley SJ. Age and cancer risk: a potentially modifiable relationship. Am J Prev Med. 2014; 46 suppl 1(3):S7-S15. [PubMed: 24512933]

7. Parry C, Kent EE, Mariotto AB, Alfano CM, Rowland JH. Cancer survivors: a booming population. Cancer Epidemiol Biomarkers Prev. 2011; 20(10):1996-2005. [PubMed: 21980007]

8. Vincent, G.; Velkoff, V. U.S. Census Bureau. The Next Four Decades: The Older Population in the United States: 2010 to 2050. Population Estimates and Projections P25-1138. Washington, DC: U.S. Department of Commerce, Economics and Statistics Administration, U.S. Census Bureau; 2010.

9. Ogden CL, Carroll MD, Kit BK, Flegal KM. Prevalence of childhood and adult obesity in the United States, 2011-2012. JAMA. 2014; 311(8):806-814. [PubMed: 24570244]

10. McTiernan A. Obesity and cancer: the risks, science, and potential management strategies. Oncology. 2005; 19(7):871-881. discussion 881-872, 885-876. [PubMed: 16053036]

11. Rock CL, Doyle C, Demark-Wahnefried W, et al. Nutrition and physical activity guidelines for cancer survivors. CA Cancer J Clin. 2012; 62(4):242-274.

12. Jacobs LA, Palmer SC, Schwartz LA, et al. Adult cancer survivorship: evolution, research, and planning care. CA Cancer J Clin. 2009; 59(6):391-410. [PubMed: 19897841]

13. Volaklis KA, Halle M, Tokmakidis SP. Exercise in the prevention and rehabilitation of breast cancer. Wien Klin Wochenschr. 2013; 125(11-12):297-301. [PubMed: 23653151]

14. Denlinger CS, Engstrom PF. Colorectal cancer survivorship: movement matters. Cancer Prev Res. 2011; 4(4):502-511.

15. Lemanne D, Cassileth B, Gubili J. The role of physical activity in cancer prevention, treatment, recovery, and survivorship. Oncology. 2013; 27(6):580-585. [PubMed: 23909073]

16. Rogers LQ, Hopkins-Price $P$, Vicari S, et al. A randomized trial to increase physical activity in breast cancer survivors. Med Sci Sports Exerc. 2009; 41(4):935-946. [PubMed: 19276838]

17. McTiernan A. Physical activity after cancer: physiologic outcomes. Cancer Invest. 2004; 22(1):6881. [PubMed: 15069764]

18. Ibrahim EM, Al-Homaidh A. Physical activity and survival after breast cancer diagnosis: metaanalysis of published studies. Med Oncol. 2011; 28(3):753-765. [PubMed: 20411366]

19. Meyerhardt JA, Giovannucci EL, Holmes MD, et al. Physical activity and survival after colorectal cancer diagnosis. J Clin Oncol. 2006; 24(22):3527-3534. [PubMed: 16822844]

20. Meyerhardt JA, Giovannucci EL, Ogino S, et al. Physical activity and male colorectal cancer survival. Arch Intern Med. 2009; 169(22):2102-2108. [PubMed: 20008694] 
21. Loprinzi PD, Lee H. Rationale for promoting physical activity among cancer survivors: literature review and epidemiologic examination. Oncol Nurs Forum. 2014; 41(2):117-125. [PubMed: 24578072]

22. Courneya, K.; Karvinen, K.; Vallance, JH. Exercise motivation and behavior change. In: Feuerstein, M., editor. Handbook of Cancer Survivorship. New York, NY: Springer; 2007. p. 113-132.

23. Pinto BM, Ciccolo JT. Physical activity motivation and cancer survivorship. Recent Results Cancer Res. 2011; 186:367-387. [PubMed: 21113773]

24. Buffart LM, Galvao DA, Brug J, Chinapaw MJ, Newton RU. Evidence-based physical activity guidelines for cancer survivors: current guidelines, knowledge gaps and future research directions. Cancer Treat Rev. 2014; 40(2):327-340. [PubMed: 23871124]

25. Courneya KS, Friedenreich CM. Physical activity and cancer control. Semin Oncol Nurs. 2007; 23(4):242-252. [PubMed: 18022052]

26. Speck RM, Courneya KS, Masse LC, Duval S, Schmitz KH. An update of controlled physical activity trials in cancer survivors: a systematic review and meta-analysis. J Cancer Surviv. 2010; 4(2):87-100. [PubMed: 20052559]

27. Brown JK, Byers T, Doyle C, et al. Nutrition and physical activity during and after cancer treatment: an American Cancer Society guide for informed choices. CA Cancer J Clin. 2003; 53(5):268-291. [PubMed: 14570227]

28. Pate RR, Pratt M, Blair SN, et al. Physical activity and public health: a recommendation from the Centers for Disease Control and Prevention and the American College of Sports Medicine. JAMA. 1995; 273(5):402-407. [PubMed: 7823386]

29. U.S. Department of Health and Human Services. [Accessed June 2, 2014] Be active your way: a fact sheet for adults. 2008. http://www.health.gov/PAGuidelines/fact-SheetAdults.aspx

30. Doyle C, Kushi LH, Byers T, et al. Nutrition and physical activity during and after cancer treatment: an American Cancer Society guide for informed choices. CA Cancer J Clin. 2006; 56(6):323-353. [PubMed: 17135691]

31. Schmitz KH, Courneya KS, Matthews C, et al. American College of Sports Medicine roundtable on exercise guidelines for cancer survivors. Med Sci Sports Exerc. 2010; 42(7):1409-1426. [PubMed: 20559064]

32. Physical Activity Guidelines Advisory Committee. Physical Activity Guidelines Advisory Committee Report, 2008. Washington, DC: U.S. Department of Health and Human Services; 2008.

33. Haskell WL, Lee IM, Pate RR, et al. Physical activity and public health: updated recommendation for adults from the American College of Sports Medicine and the American Heart Association. Circulation. 2007; 116(9):1081-1093. [PubMed: 17671237]

34. Ottenbacher A, Yu M, Moser RP, Phillips SM, Alfano C, Perna FM. Population estimates of meeting strength training and aerobic guidelines, by gender and cancer survivorship status: findings from the Health Information National Trends Survey (HINTS). J Phys Act Health. [published online May 15, 2014].

35. Bellizzi KM, Rowland JH, Jeffery DD, McNeel T. Health behaviors of cancer survivors: examining opportunities for cancer control intervention. J Clin Oncol. 2005; 23(34):8884-8893. [PubMed: 16314649]

36. Courneya KS, Katzmarzyk PT, Bacon E. Physical activity and obesity in Canadian cancer survivors: population-based estimates from the 2005 Canadian Community Health Survey. Cancer. 2008; 112(11):2475-2482. [PubMed: 18428195]

37. Speck RM, Courneya KS, Masse LC, Duval S, Schmitz KH. An update of controlled physical activity trials in cancer survivors: a systematic review and meta-analysis. J Cancer Surviv Res Pract. 2011; 5(1):112. (vol 4, pg 87, 2010).

38. Schmitz KH. Balancing lymphedema risk: exercise versus deconditioning for breast cancer survivors. Exerc Sport Sci Rev. 2010; 38(1):17-24. [PubMed: 20016295]

39. Chang CJ, Cormier JN. Lymphedema interventions: exercise, surgery, and compression devices. Semin Oncol Nurs. 2013; 29(1):28-40. [PubMed: 23375064] 
40. Bourke L, Homer KE, Thaha MA, et al. Interventions to improve exercise behaviour in sedentary people living with and beyond cancer: a systematic review. Br J Cancer. 2014; 110(4):831-841. [PubMed: 24335923]

41. Demark-Wahnefried W, Clipp EC, Lipkus IM, et al. Main outcomes of the FRESH START trial: a sequentially tailored, diet and exercise mailed print intervention among breast and prostate cancer survivors. J Clin Oncol. 2007; 25(19):2709-2718. [PubMed: 17602076]

42. Irwin ML, Cadmus L, Alvarez-Reeves M, et al. Recruiting and retaining breast cancer survivors into a randomized controlled exercise trial: the Yale Exercise and Survivorship Study. Cancer. 2008; 112 suppl(11):2593-2606. [PubMed: 18428192]

43. McGowan EL, North S, Courneya KS. Randomized controlled trial of a behavior change intervention to increase physical activity and quality of life in prostate cancer survivors. Ann Behav Med. 2013; 46(3):382-393. [PubMed: 23783829]

44. Courneya KS, Booth CM, Gill S, et al. The Colon Health and Life-Long Exercise Change trial: a randomized trial of the National Cancer Institute of Canada Clinical Trials Group. Curr Oncol. 2008; 15(6):279-285. [PubMed: 19079628]

45. Mitchell NS, Catenacci VA, Wyatt HR, Hill JO. Obesity: overview of an epidemic. Psychiatr Clin North Am. 2011; 34(4):717-732. [PubMed: 22098799]

46. Peters JC, Wyatt HR, Donahoo WT, Hill JO. From instinct to intellect: the challenge of maintaining healthy weight in the modern world. Obes Rev. 2002; 3(2):69-74. [PubMed: 12120422]

47. Hill JO, Wyatt HR, Melanson EL. Genetic and environmental contributions to obesity. Med Clin North Am. 2000; 84(2):333-346. [PubMed: 10793645]

48. Hill JO, Wyatt HR, Peters JC. Energy balance and obesity. Circulation. 2012; 126(1):126-132. [PubMed: 22753534]

49. Donnelly JE, Smith B, Jacobsen DJ, et al. The role of exercise for weight loss and maintenance. Best Pract Res Clin Gastroenterol. 2004; 18(6):1009-1029. [PubMed: 15561636]

50. Hawkes AL, Chambers SK, Pakenham KI, et al. Effects of a telephone-delivered multiple health behavior change intervention (CanChange) on health and behavioral outcomes in survivors of colorectal cancer: a randomized controlled trial. J Clin Oncol. 2013; 31(18):2313-2321. [PubMed: 23690410]

51. Demark-Wahnefried W, Morey MC, Sloane R, et al. Reach out to enhance wellness home-based diet-exercise intervention promotes reproducible and sustainable long-term improvements in health behaviors, body weight, and physical functioning in older, overweight/obese cancer survivors. J Clin Oncol. 2012; 30(19):2354-2361. [PubMed: 22614994]

52. von Gruenigen V, Frasure H, Kavanagh MB, et al. Survivors of uterine cancer empowered by exercise and healthy diet (SUCCEED): a randomized controlled trial. Gynecol Oncol. 2012; 125(3):699-704. [PubMed: 22465522]

53. Peterson MD, Sen A, Gordon PM. Influence of resistance exercise on lean body mass in aging adults: a meta-analysis. Med Sci Sports Exerc. 2011; 43(2):249-258. [PubMed: 20543750]

54. Antoun S, Borget I, Lanoy E. Impact of sarcopenia on the prognosis and treatment toxicities in patients diagnosed with cancer. Curr Opin Support Palliat Care. 2013; 7(4):383-389. [PubMed: 24189893]

55. Prado CM, Baracos VE, McCargar LJ, et al. Sarcopenia as a determinant of chemotherapy toxicity and time to tumor progression in metastatic breast cancer patients receiving capecitabine treatment. Clin Cancer Res. 2009; 15(8):2920-2926. [PubMed: 19351764]

56. Demark-Wahnefried W, Kenyon AJ, Eberle P, Skye A, Kraus WE. Preventing sarcopenic obesity among breast cancer patients who receive adjuvant chemotherapy: results of a feasibility study. Clin Exerc Physiol. 2002; 4(1):44-49. [PubMed: 16946801]

57. Demark-Wahnefried W, Winer EP, Rimer BK. Why women gain weight with adjuvant chemotherapy for breast cancer. J Clin Oncol. 1993; 11(7):1418-1429. [PubMed: 8315439]

58. Prado CM, Lieffers JR, Bowthorpe L, Baracos VE, Mourtzakis M, McCargar LJ. Sarcopenia and physical function in overweight patients with advanced cancer. Can J Diet Pract Res. 2013; 74(2): 69-74. [PubMed: 23750978] 
59. Villasenor A, Ballard-Barbash R, Baumgartner K, et al. Prevalence and prognostic effect of sarcopenia in breast cancer survivors: the HEAL study. J Cancer Surviv Res Pract. 2012; 6(4): 398-406.

60. Broderick JM, Ryan J, O'Donnell DM, Hussey J. A guide to assessing physical activity using accelerometry in cancer patients. Support Care Cancer. 2014; 22(4):1121-1130. [PubMed: 24389829]

61. Pinto BM, Rabin C, Dunsiger S. Home-based exercise among cancer survivors: adherence and its predictors. Psychooncology. 2009; 18(4):369-376. [PubMed: 19242921]

62. Courneya KS, Friedenreich CM, Quinney HA, Fields AL, Jones LW, Fairey AS. Predictors of adherence and contamination in a randomized trial of exercise in colorectal cancer survivors. Psychooncology. 2004; 13(12):857-866. [PubMed: 15386794]

63. Jones SB, Thomas GA, Hesselsweet SD, Alvarez-Reeves M, Yu H, Irwin ML. Effect of exercise on markers of inflammation in breast cancer survivors: the Yale Exercise and Survivorship Study. Cancer Prev Res. 2013; 6(2):109-118.

64. Irwin ML, McTiernan A, Manson JE, et al. Physical activity and survival in postmenopausal women with breast cancer: results from the Women's Health Initiative. Cancer Prev Res. 2011; 4(4):522-529.

65. Sternfeld B, Weltzien E, Quesenberry CP Jr, et al. Physical activity and risk of recurrence and mortality in breast cancer survivors: findings from the LACE study. Cancer Epidemiol Biomarkers Prev. 2009; 18(1):87-95. [PubMed: 19124485]

66. Irwin ML, Ainsworth BE, Conway JM. Estimation of energy expenditure from physical activity measures: determinants of accuracy. Obes Res. 2001; 9(9):517-525. [PubMed: 11557832]

67. Prince SA, Adamo KB, Hamel ME, Hardt J, Connor Gorber S, Tremblay M. A comparison of direct versus self-report measures for assessing physical activity in adults: a systematic review. Int J Behav Nutr Phys Act. 2008; 5:56. [PubMed: 18990237]

68. Schmitz KH, Holtzman J, Courneya KS, Masse LC, Duval S, Kane R. Controlled physical activity trials in cancer survivors: a systematic review and meta-analysis. Cancer Epidemiol Biomarkers Prev. 2005; 14(7):1588-1595. [PubMed: 16030088]

69. Bassett DR Jr, Mahar MT, Rowe DA, Morrow JR Jr. Walking and measurement. Med Sci Sports Exerc. 2008; 40 suppl(7):S529-S536. [PubMed: 18562970]

70. Vallance JK, Courneya KS, Plotnikoff RC, Yasui Y, Mackey JR. Randomized controlled trial of the effects of print materials and step pedometers on physical activity and quality of life in breast cancer survivors. J Clin Oncol. 2007; 25(17):2352-2359. [PubMed: 17557948]

71. Frensham LJ, Zarnowiecki DM, Parfitt G, Stanley RM, Dollman J. Steps Toward Improving Diet and Exercise for Cancer Survivors (STRIDE): a quasi-randomised controlled trial protocol. BMC Cancer. 2014; 14(1):428. 13. [PubMed: 24923623]

72. Blair CK, Morey MC, Desmond RA, et al. Light-intensity activity attenuates functional decline in older cancer survivors. Med Sci Sports Exerc. 2014; 46(7):1375-1383. [PubMed: 24389524]

73. Mishra SI, Scherer RW, Snyder C, Geigle PM, Berlanstein DR, Topaloglu O. Exercise interventions on health-related quality of life for people with cancer during active treatment. Cochrane Database Syst Rev. 2012; 8:CD008465. [PubMed: 22895974]

74. Rogers LQ. Objective monitoring of physical activity after a cancer diagnosis: challenges and opportunities for enhancing cancer control. Phys Ther Rev. 2010; 15(3):224-237. [PubMed: 21603254]

75. Maddocks M, Wilcock A. Exploring physical activity level in patients with thoracic cancer: implications for use as an outcome measure. Support Care Cancer. 2012; 20(5):1113-1116. [PubMed: 22311375]

76. Thompson WG, Kuhle CL, Koepp GA, McCrady-Spitzer SK, Levine JA. "Go4Life” exercise counseling, accelerometer feedback, and activity levels in older people. Arch Gerontol Geriatr. 2014; 58(3):314-319. [PubMed: 24485546]

77. McNeely ML, Campbell KL, Rowe BH, Klassen TP, Mackey JR, Courneya KS. Effects of exercise on breast cancer patients and survivors: a systematic review and meta-analysis. CMAJ. 2006; 175(1):34-41. [PubMed: 16818906] 
78. Courneya KS, Friedenreich CM, Quinney HA, Fields AL, Jones LW, Fairey AS. A randomized trial of exercise and quality of life in colorectal cancer survivors. Eur J Cancer Care. 2003; 12(4): 347-357.

79. Thorsen L, Courneya KS, Stevinson C, Fossa SD. A systematic review of physical activity in prostate cancer survivors: outcomes, prevalence, and determinants. Support Care Cancer. 2008; 16(9):987-997. [PubMed: 18274783]

80. Liu RD, Chinapaw MJ, Huijgens PC, van Mechelen W. Physical exercise interventions in haematological cancer patients, feasible to conduct but effectiveness to be established: a systematic literature review. Cancer Treat Rev. 2009; 35(2):185-192. [PubMed: 19004560]

81. Lee DC, Artero EG, Sui X, Blair SN. Mortality trends in the general population: the importance of cardiorespiratory fitness. J Psychopharmacol. 2010; 24 suppl(4):27-35. [PubMed: 20923918]

82. Burnett D, Kluding P, Porter C, Fabian C, Klemp J. Cardiorespiratory fitness in breast cancer survivors. SpringerPlus. 2013; 2(1):68. [PubMed: 23538987]

83. Klassen O, Schmidt ME, Scharhag-Rosenberger F, et al. Cardiorespiratory fitness in breast cancer patients undergoing adjuvant therapy. Acta Oncol. [published online May 16, 2010].

84. Hayes S, Rye S, Battistutta D, et al. Design and implementation of the Exercise for Health trial-a pragmatic exercise intervention for women with breast cancer. Contemp Clin Trials. 2011; 32(4): 577-585. [PubMed: 21463707]

85. Bourke L, Doll H, Crank H, Daley A, Rosario D, Saxton JM. Lifestyle intervention in men with advanced prostate cancer receiving androgen suppression therapy: a feasibility study. Cancer Epidemiol Biomarkers Prev. 2011; 20(4):647-657. [PubMed: 21335510]

86. Strasser B, Steindorf K, Wiskemann J, Ulrich CM. Impact of resistance training in cancer survivors: a meta-analysis. Med Sci Sports Exerc. 2013; 45(11):2080-2090. [PubMed: 23669878]

87. Cormie P, Pumpa K, Galvao DA, et al. Is it safe and efficacious for women with lymphedema secondary to breast cancer to lift heavy weights during exercise: a randomised controlled trial. J Cancer Surviv Res Pract. 2013; 7(3):413-424.

88. Schmitz KH, Ahmed RL, Troxel AB, et al. Weight lifting for women at risk for breast cancerrelated lymphedema: a randomized trial. JAMA. 2010; 304(24):2699-2705. [PubMed: 21148134]

89. Schmitz KH, Ahmed RL, Troxel A, et al. Weight lifting in women with breast-cancer-related lymphedema. N Engl J Med. 2009; 361(7):664-673. [PubMed: 19675330]

90. Waltman NL, Twiss JJ, Ott CD, et al. The effect of weight training on bone mineral density and bone turnover in postmenopausal breast cancer survivors with bone loss: a 24-month randomized controlled trial. Osteoporosis Int. 2010; 21(8):1361-1369.

91. Speck RM, Gross CR, Hormes JM, et al. Changes in the Body Image and Relationship Scale following a one-year strength training trial for breast cancer survivors with or at risk for lymphedema. Breast Cancer Res Treat. 2010; 121(2):421-430. [PubMed: 19771507]

92. Cantarero-Villanueva I, Fernandez-Lao C, Cuesta-Vargas AI, Del Moral-Avila R, Fernandez-deLas-Penas C, Arroyo-Morales M. The effectiveness of a deep water aquatic exercise program in cancer-related fatigue in breast cancer survivors: a randomized controlled trial. Arch Phys Med Rehabil. 2013; 94(2):221-230. [PubMed: 23017985]

93. Santa Mina D, Alibhai SM, Matthew AG, et al. A randomized trial of aerobic versus resistance exercise in prostate cancer survivors. J Aging Phys Act. 2013; 21(4):455-478. [PubMed: 23238110]

94. Galvao DA, Taaffe DR, Spry N, Joseph D, Newton RU. Combined resistance and aerobic exercise program reverses muscle loss in men undergoing androgen suppression therapy for prostate cancer without bone metastases: a randomized controlled trial. J Clin Oncol. 2010; 28(2):340-347. [PubMed: 19949016]

95. Burnham TR, Wilcox A. Effects of exercise on physiological and psychological variables in cancer survivors. Med Sci Sports Exerc. 2002; 34(12):1863-1867. [PubMed: 12471288]

96. Courneya KS, Friedenreich CM, Sela RA, Quinney HA, Rhodes RE, Handman M. The group psychotherapy and home-based physical exercise (group-hope) trial in cancer survivors: physical fitness and quality of life outcomes. Psychooncology. 2003; 12(4):357-374. [PubMed: 12748973] 
97. Mustian KM, Katula JA, Zhao H. A pilot study to assess the influence of tai chi chuan on functional capacity among breast cancer survivors. J Support Oncol. 2006; 4(3):139-145. [PubMed: 16553140]

98. Mustian KM, Palesh OG, Flecksteiner SA. Tai chi chuan for breast cancer survivors. Med Sport Sci. 2008; 52:209-217. [PubMed: 18487900]

99. Van Puymbroeck M, Schmid A, Shinew KJ, Hsieh PC. Influence of Hatha yoga on physical activity constraints, physical fitness, and body image of breast cancer survivors: a pilot study. Int J Yoga Ther. 2011; (21):49-60.

100. Kilgour RD, Jones DH, Keyserlingk JR. Effectiveness of a self-administered, home-based exercise rehabilitation program for women following a modified radical mastectomy and axillary node dissection: a preliminary study. Breast Cancer Res Treat. 2008; 109(2):285-295. [PubMed: 17624606]

101. Wiseman M. The second World Cancer Research Fund/American Institute for Cancer Research expert report: food, nutrition, physical activity, and the prevention of cancer: a global perspective. Proc Nutr Soc. 2008; 67(3):253-256. [PubMed: 18452640]

102. Smith WA, Li C, Nottage KA, et al. Lifestyle and metabolic syndrome in adult survivors of childhood cancer: a report from the St. Jude Lifetime Cohort Study. Cancer. 2014; 120(17): 2742-2750. [PubMed: 25070001]

103. King M-C, Marks JH, Mandell JB. Breast and ovarian cancer risks due to inherited mutations in BRCA1 and BRCA2. Science. 2003; 302(5645):643-646. [PubMed: 14576434]

104. McTiernan A. Mechanisms linking physical activity with cancer. Nat Rev Cancer. 2008; 8(3): 205-211. [PubMed: 18235448]

105. Ulrich CM, Wiskemann J, Steindorf K. Physiologic and molecular mechanisms linking physical activity to cancer risk and progression [in German]. Bundesgesundheitsblatt Gesundheitsforschung Gesundheitsschutz. 2012; 55(1):3-9. [PubMed: 22286244]

106. Irwin ML, McTiernan A, Bernstein L, et al. Relationship of obesity and physical activity with Cpeptide, leptin, and insulin-like growth factors in breast cancer survivors. Cancer Epidemiol Biomarkers Prev. 2005; 14(12):2881-2888. [PubMed: 16365005]

107. Pierce BL, Neuhouser ML, Wener MH, et al. Correlates of circulating C-reactive protein and serum amyloid A concentrations in breast cancer survivors. Breast Cancer Res Treat. 2009; 114(1):155-167. [PubMed: 18401703]

108. Ballard-Barbash R, Friedenreich CM, Courneya KS, Siddiqi SM, McTiernan A, Alfano CM. Physical activity, biomarkers, and disease outcomes in cancer survivors: a systematic review. J Natl Cancer Inst. 2012; 104(11):815-840. [PubMed: 22570317]

109. Ligibel JA, Campbell N, Partridge A, et al. Impact of a mixed strength and endurance exercise intervention on insulin levels in breast cancer survivors. J Clin Oncol. 2008; 26(6):907-912. [PubMed: 18281663]

110. Zeng YC, Huang ML, Cheng A, Zhou Y, So WKW. Meta-analysis of the effects of exercise intervention on quality of life in breast cancer survivors. Breast Cancer. 2014; 21(3):262-274. [PubMed: 24569944]

111. Demark-Wahnefried W, Morey MC, Clipp EC, et al. Leading the Way in Exercise and Diet (Project LEAD): intervening to improve function among older breast and prostate cancer survivors. Control Clin Trials. 2003; 24(2):206-223. [PubMed: 12689742]

112. Ferrer RA, Huedo-Medina TB, Johnson BT, Ryan S, Pescatello LS. Exercise interventions for cancer survivors: a meta-analysis of quality of life outcomes. Ann Behav Med. 2011; 41(1):3247. [PubMed: 20931309]

113. Basen-Engquist K, Carmack C, Brown J, et al. Response to an exercise intervention after endometrial cancer: differences between obese and non-obese survivors. Gynecol Oncol. 2014; 133(1):48-55. [PubMed: 24680591]

114. Carmack Taylor CL, Demoor C, Smith MA, et al. Active for Life After Cancer: a randomized trial examining a lifestyle physical activity program for prostate cancer patients. Psychooncology. 2006; 15(10):847-862. [PubMed: 16447306]

115. Hayes SC, Rye S, Disipio T, et al. Exercise for health: a randomized, controlled trial evaluating the impact of a pragmatic, translational exercise intervention on the quality of life, function and 
treatment-related side effects following breast cancer. Breast Cancer Res Treat. 2013; 137(1): 175-186. [PubMed: 23139058]

116. Courneya KS, Segal RJ, Mackey JR, et al. Effects of aerobic and resistance exercise in breast cancer patients receiving adjuvant chemotherapy: a multicenter randomized controlled trial. J Clin Oncol. 2007; 25(28):4396-4404. [PubMed: 17785708]

117. Ryan JL, Carroll JK, Ryan EP, Mustian KM, Fiscella K, Morrow GR. Mechanisms of cancerrelated fatigue. Oncologist. 2007; 12(suppl 1):22-34. [PubMed: 17573453]

118. Gandevia SC. Spinal and supraspinal factors in human muscle fatigue. Physiol Rev. 2001; 81(4): 1725-1789. [PubMed: 11581501]

119. Chaudhuri A, Behan PO. Fatigue in neurological disorders. Lancet. 2004; 363(9413):978-988. [PubMed: 15043967]

120. Bower JE, Ganz PA, Aziz N, Fahey JL. Fatigue and proinflammatory cytokine activity in breast cancer survivors. Psychosom Med. 2002; 64(4):604-611. [PubMed: 12140350]

121. Wratten C, Kilmurray J, Nash S, et al. Fatigue during breast radiotherapy and its relationship to biological factors. Int J Radiat Oncol Biol Phys. 2004; 59(1):160-167. [PubMed: 15093912]

122. Bower JE. Cancer-related fatigue-mechanisms, risk factors, and treatments. Nat Rev Clin Oncol. [published online August 12, 2014].

123. National Comprehensive Cancer Network. NCCN Clinical Practice Guidelines in Oncology: Cancer-Related Fatigue: Version 1.2013. Fort Washington, PA: National Comprehensive Cancer Network; 2012.

124. Wang XS, Zhao F, Fisch MJ, et al. Prevalence and characteristics of moderate to severe fatigue: a multicenter study in cancer patients and survivors. Cancer. 2014; 120(3):425-432. [PubMed: 24436136]

125. Buffart LM, De Backer IC, Schep G, Vreugdenhil A, Brug J, Chinapaw MJ. Fatigue mediates the relationship between physical fitness and quality of life in cancer survivors. J Sci Med Sport. 2013; 16(2):99-104. [PubMed: 22749527]

126. Phillips SM, McAuley E. Physical activity and fatigue in breast cancer survivors: a panel model examining the role of self-efficacy and depression. Cancer Epidemiol Biomarkers Prev. 2013; 22(5):773-781. [PubMed: 23456557]

127. Cramp F, Byron-Daniel J. Exercise for the management of cancer-related fatigue in adults. Cochrane Database Syst Rev. 2012; 11:CD006145. [PubMed: 23152233] 


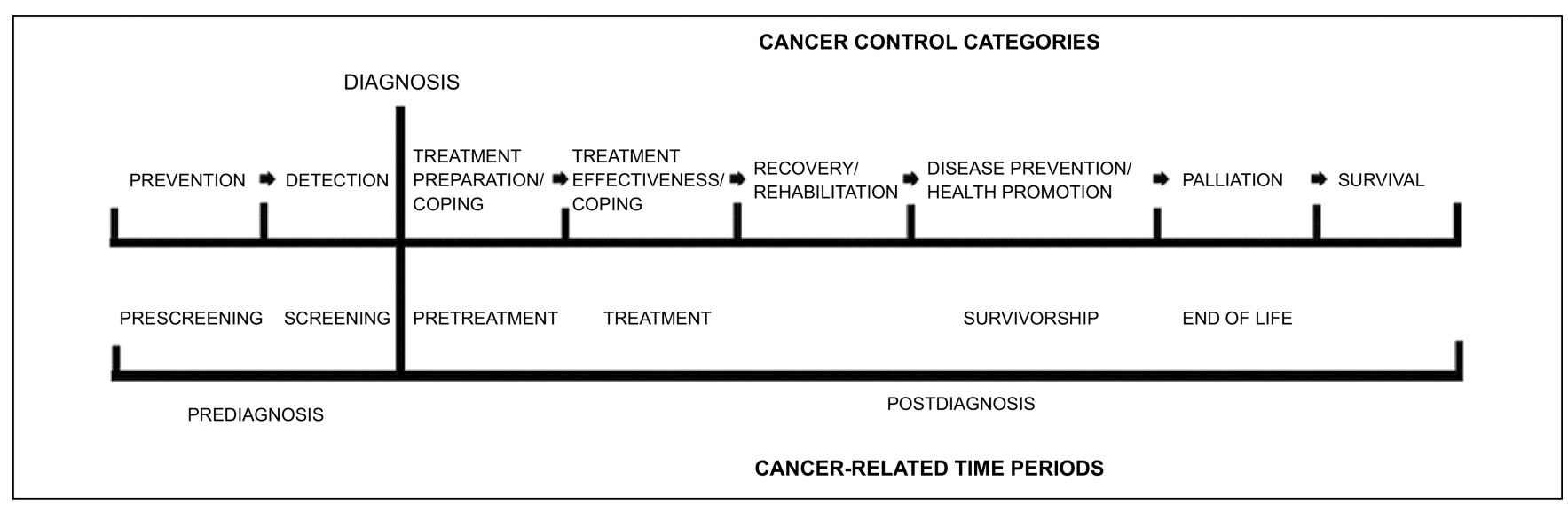

Figure 1.

Physical activity and cancer control framework. From Courneya KS, Friedenreich CM. Physical activity and cancer control. Semin Oncol Nurs. 2007;23(4):242-252. Copyright 2007. Reprinted with permission from Elsevier. 


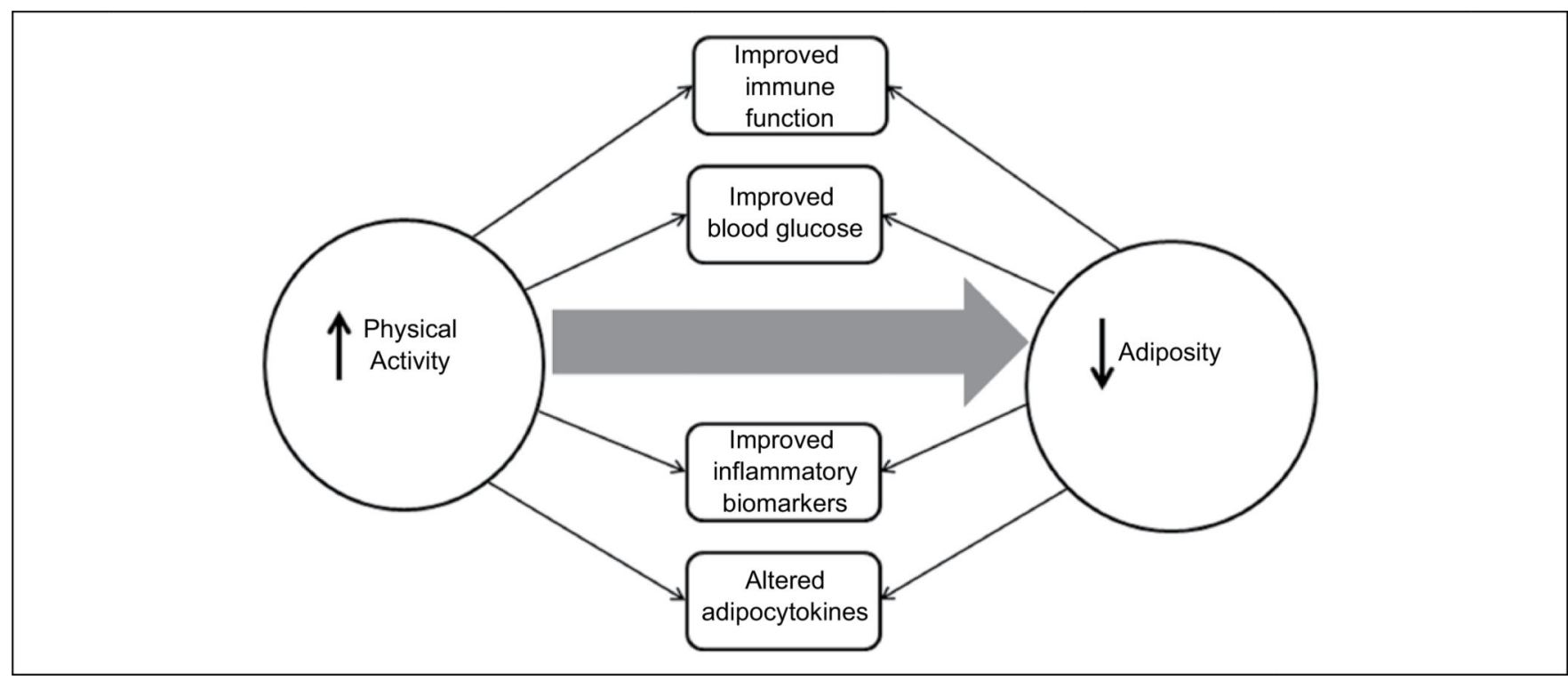

Figure 2.

Cardiometabolic measures influenced by increasing physical activity. 


\section{Table 1}

\section{Summary of Physical Activity Guidelines for Cancer Survivors.}

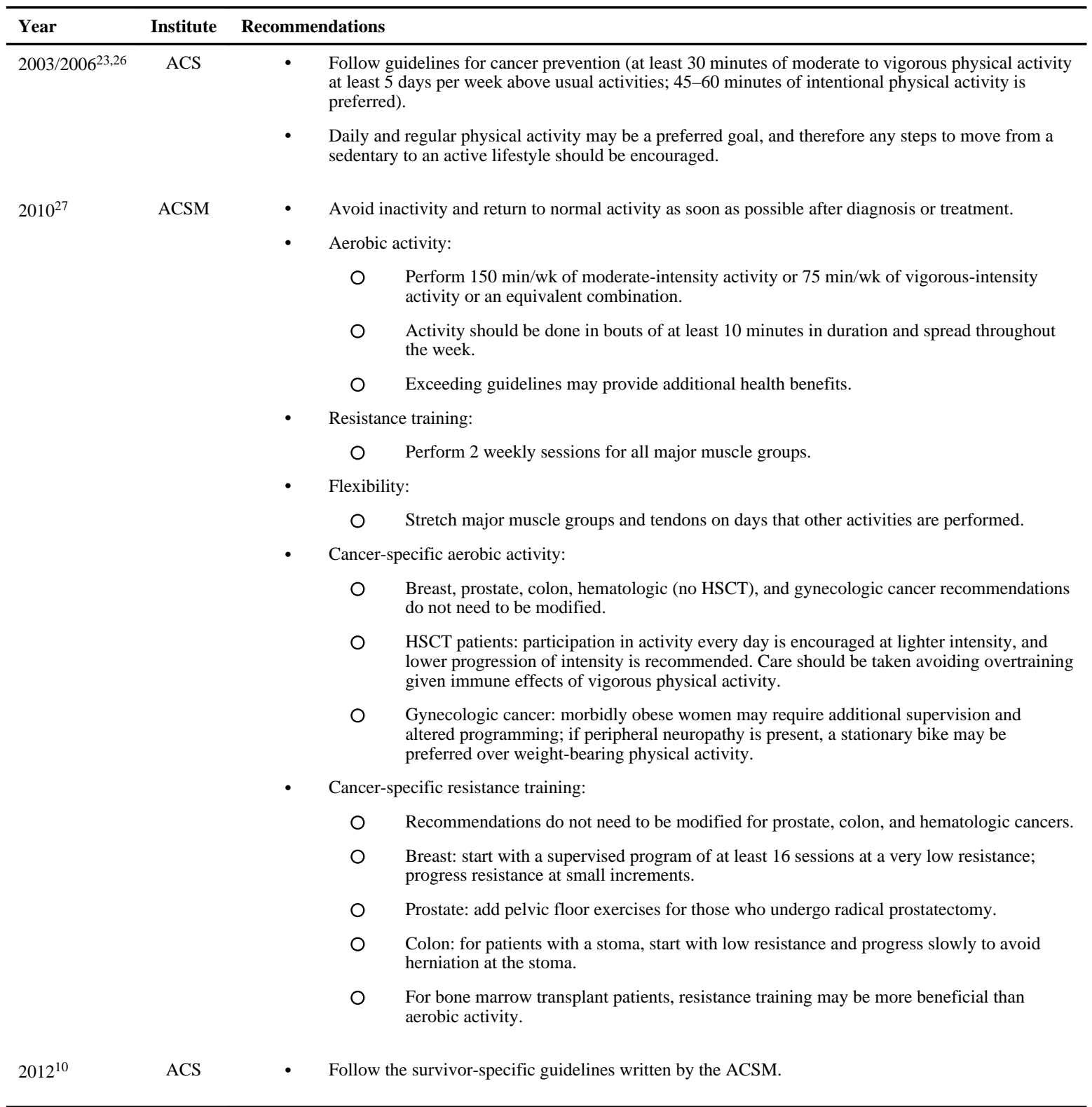

ACS, American Cancer Society; ACSM, American College of Sports Medicine; HSCT, hematopoietic stem cell transplantation. 


\section{Table 2}

Examples of Moderate and Vigorous Activities.

\begin{tabular}{l}
$\begin{array}{l}\text { Moderate Activities } \\
\text { (You can talk while you do them but not sing.) }\end{array}$ \\
\hline - $\quad$ Ballroom and line dancing \\
- $\quad$ Biking on level ground with few hills \\
- $\quad$ Canoeing \\
- $\quad$ General gardening (raking, trimming shrubs) \\
- $\quad \begin{array}{l}\text { Sports where you catch and throw (baseball, softball, } \\
\text { volleyball) }\end{array}$ \\
- $\quad$ Walking briskly \\
$\quad$ Water aerobics
\end{tabular}

Vigorous Activities

(You can only say a few words without stopping to catch your breath.)

- Aerobic dance

- $\quad$ Fast dancing

- $\quad$ Biking faster than 10 miles per hour

- Heavy gardening (digging, hoeing)

- $\quad$ Hiking uphill

- Jumping rope

- Jogging/running

- Swimming laps

- Tennis (singles)

Data from Courneya and Friedenreich. ${ }^{25}$ Table reprinted from Rock CL, Doyle C, Demark-Wahnefried W, et al. Nutrition and physical activity guidelines for cancer survivors. CA Cancer J Clin. 2012;62:242-274. Copyright 2012 American Cancer Society, Inc. Reprinted with permission from John Wiley and Sons. 
Table 3

Safety Precautions and Contraindications to Physical Activity for Cancer Survivors.

\begin{tabular}{|c|c|c|}
\hline Year & Institute & Safety Precautions and Contraindications \\
\hline \multirow[t]{7}{*}{$2003 / 2006 / 2012^{10,23,26}$} & ACS & $\begin{array}{l}\text { - Survivors with compromised immune function should avoid public gyms and public pools } \\
\text { until their white blood cell counts return to safe levels. }\end{array}$ \\
\hline & & $\begin{array}{l}\text { - Survivors who have completed a bone marrow transplant are usually advised to avoid such } \\
\text { exposures for } 1 \text { year after transplantation. }\end{array}$ \\
\hline & & $\begin{array}{l}\text { Survivors experiencing severe fatigue from their therapy may not feel up to an exercise } \\
\text { program, and therefore they may be encouraged to do } 10 \text { minutes of light exercises daily. }\end{array}$ \\
\hline & & $\begin{array}{l}\text { - Survivors undergoing radiation should avoid chlorine exposure to irradiated skin (eg, from } \\
\text { swimming pools). }\end{array}$ \\
\hline & & $\begin{array}{l}\text { Survivors with indwelling catheters or feeding tubes should be cautious or avoid pool, lake, } \\
\text { or ocean water or other microbial exposures that may result in infections, as well as resistance } \\
\text { training of muscles in the area of the catheter to avoid dislodgment. }\end{array}$ \\
\hline & & $\begin{array}{l}\text { - Survivors with multiple or uncontrolled comorbidities need to consider modifications to their } \\
\text { exercise program in consultation with their physicians. }\end{array}$ \\
\hline & & $\begin{array}{l}\text { - Survivors with significant peripheral neuropathies or ataxia may have a reduced ability to use } \\
\text { the affected limbs because of weakness or loss of balance. They may do better with a } \\
\text { stationary reclining bicycle, for example, than walking on a treadmill. }\end{array}$ \\
\hline \multirow[t]{9}{*}{$2010^{27}$} & ACSM & $\begin{array}{l}\text { Beware of fracture risk in patients with breast and prostate cancer who are treated with } \\
\text { hormone or androgen deprivation therapy, respectively, or diagnosed with osteoporosis or } \\
\text { bone metastases. }\end{array}$ \\
\hline & & $\begin{array}{l}\text { Women with immediate arm or shoulder problems secondary to breast cancer treatment } \\
\text { should seek medical care to resolve those issues before exercise training with the upper body. }\end{array}$ \\
\hline & & $\begin{array}{l}\text { - If an ostomy is present in patients with colon cancer, physician permission is recommended } \\
\text { before participation in contact sport and weight training, excessive intra-abdominal pressure } \\
\text { should be avoided, and modifications will be needed for swimming and contact sports. }\end{array}$ \\
\hline & & $\begin{array}{l}\text { - In adults with HSCT, care should be taken to avoiding overtraining given immune effects of } \\
\text { vigorous exercise. }\end{array}$ \\
\hline & & $\begin{array}{l}\text { - If peripheral neuropathy is present in patients with gynecologic cancer, a stationary bike } \\
\text { might be preferable over weight-bearing exercise. }\end{array}$ \\
\hline & & $\begin{array}{l}\text { Women with gynecologic cancer with swelling or inflammation of the abdomen, groin, or } \\
\text { lower extremities should seek medical care to resolve these issues before exercise training } \\
\text { with the lower body. }\end{array}$ \\
\hline & & $\begin{array}{l}\text { - Patients with bone metastases may need to alter their exercise program given the increased } \\
\text { risk for skeletal fractures. }\end{array}$ \\
\hline & & $\begin{array}{l}\text { - Care should be taken to reduce infection risk in fitness centers for patients who are currently } \\
\text { undergoing chemotherapy or radiation treatment or have compromised immune function. }\end{array}$ \\
\hline & & $\begin{array}{l}\text { Patients with cardiac conditions will require modifications and may require increased } \\
\text { supervision for safety. }\end{array}$ \\
\hline
\end{tabular}

ACS, American Cancer Society; ACSM, American College of Sports Medicine; HSCT, hematopoietic stem cell transplantation. 